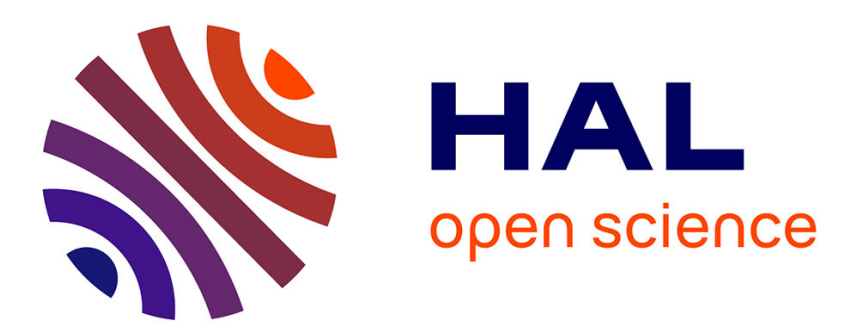

\title{
Analyzing hydrocarbons in sewer to help in PAH source apportionment in sewage sludges
}

Laurence Mansuy, Annette Regier, Pierre Faure

\section{To cite this version:}

Laurence Mansuy, Annette Regier, Pierre Faure. Analyzing hydrocarbons in sewer to help in PAH source apportionment in sewage sludges. Chemosphere, 2009, 75 (8), pp.995-1002. 10.1016/j.chemosphere.2009.01.059 . hal-01760357

\section{HAL Id: hal-01760357 \\ https://hal.univ-lorraine.fr/hal-01760357}

Submitted on 6 Apr 2018

HAL is a multi-disciplinary open access archive for the deposit and dissemination of scientific research documents, whether they are published or not. The documents may come from teaching and research institutions in France or abroad, or from public or private research centers.
L'archive ouverte pluridisciplinaire HAL, est destinée au dépôt et à la diffusion de documents scientifiques de niveau recherche, publiés ou non, émanant des établissements d'enseignement et de recherche français ou étrangers, des laboratoires publics ou privés. 


\section{Analyzing hydrocarbons in sewer to help in PAH source}

\section{apportionment in sewage sludges}

18 G2R, Nancy-Université, CNRS, Bd des Aiguillettes, B.P. 70239, F-54506 Vandœuvre-lès-

19 Nancy

20

21 Corresponding author: Laurence Mansuy-Huault

22 Tel: +33-3-83-68-47-12; Fax: +33-3-83-68-47-01

23 E-mail address: Laurence.mansuy-huault@g2r.uhp-nancy.fr 


\section{Analyzing hydrocarbons in sewer to help in PAH source apportionment in}

sewage sludges

G2R, Nancy-Université, CNRS, Bd des Aiguillettes, B.P. 70239, F-54506 Vandœuvre-lès-

Nancy

\section{Abstract}

A multi-molecular approach for polycyclic aromatic hydrocarbons (PAH) source apportionment in sewage sludge was tested. Three simple catchment areas with corresponding wastewater treatment plants (WWTP) were chosen. Sewage sludges of these WWTPs chronically exceeded the French guide values of PAHs. Aliphatic and aromatic hydrocarbons were quantified in sediments or wastewater suspended particulate matter sampled in different locations of the sewer as well as in sewage sludges. Various molecular indices including PAH ratios were calculated. The results showed that the ratios calculated from sewage sludge analyses provided a rather unspecific hydrocarbon fingerprint where combustion input appear as the main PAH sources. The complexity of the inputs as well as degradation occurring during wastewater treatment prevent any detailed diagnosis. Coupled to the analyses of samples collected in the sewer, the multi-molecular approach becomes more efficient especially for the identification of specific petroleum inputs such as fuel or used lubricating oils which can be important PAH sources. Indeed, the sampling in the sewer allows a spatial screening of the hydrocarbon inputs and facilitates the PAH source apportionment by avoiding the dilution of specific inputs with the whole wastewater inputs and by limiting the degradation of the molecular fingerprint that could occur'during transfer and treatment in the WWTP. Then, the combination of PAH ratios and aliphatic distribution analyses is a very valuable approach that can help in sewer and WWTP management. 
PAHs in sewage sludges have many sources related to the intense use of petroleum

59 products (automobile fuels, lubricating oils...) or to combustion processes (fuel, wood and

60 coal burning, automobile exhaust, heat and power generation ...). They end up in sewage

61 sludges (i) by runoff on urbanized surfaces and (ii) by direct introduction into the sewer by

62 industrial effluents, accidents or individual spillage. They are diluted with organic compounds

63 brought with wastewater, partially degraded in the wastewater treatment plant (WWTP) and

64 eventually accumulate in sewage sludges.

High PAH contamination can be recorded all along the year or chronically in sewage sludges produced by the WWTPs of some cities or even small rural districts. The French regulation allows sludge amendments on agricultural soils when fluoranthene, benzo[b]fluoranthene and benzo[a]pyrene are respectively lower than $5 \mu \mathrm{g} \cdot \mathrm{g}^{-1}$ dry weight (dw), $2.5 \mu \mathrm{g} \cdot \mathrm{g}^{-1} \mathrm{dw}$ and $2 \mu \mathrm{g} \cdot \mathrm{g}^{-1} \mathrm{dw}$. The other ways of elimination of sludges are much more expensive and this cost is sometimes unbearable for small villages. Thus, the knowledge of the main PAH sources is crucial information to help improving the management of effluents that enter the sewer network, to better define the type of wastewater treatment, or to better inform citizens about what should not be dumped into the sewer.

There are several ways to identify PAH sources. The most common is to study PAH distributions and to use specific $\mathrm{PAH}$ ratios to differentiate pyrogenic sources from petrogenic sources. This has been mainly applied to river or marine sediments (Colombo et al., 1989;

78 Budzinski et al., 1997; Yunker et al., 2002), atmospheric particles (Aboul-Kassim and 79 Simoneit, 1995; Motelay-Massei et al., 2007), soils (Wilcke, 2000; Bucheli et al., 2004), in 80 sewers, sewage sludges or in compost (Blanchard et al., 2001; Rocher et al., 2004a,b; Brandli 81 et al., 2007; Dai et al., 2007). Recently, Zhang et al. (2005) and Katsoyiannis et al. (2007) 
82 questioned the pertinence of PAH ratios for source apportionment especially in sewage sludge

83 arguing the dilution and the degradation of paired chemicals are not similar during transfer

84 from sources to receptors. Some authors consider PAH profiles and ratios as insufficiently

85 specific to identify petroleum pollution and suggest to support $\mathrm{PAH}$ diagnosis with the

86 analyses of other hydrocarbon fingerprints such as alkanes and hopanes in order to narrow

87 down the sources (Fernandes and Brooks, 2003; Yunker and Macdonald, 2003; Jardé et al.,

88 2005; Jeanneau et al., 2008).

89 This study discusses the approach of molecular indices calculated from hydrocarbon

90 analysis to help in identifying prevailing sources of PAH in sewage sludges. Three WWTPs

91 in small rural districts have been selected for their chronic or permanent PAH contamination,

92 for the simple network of their sewer and the low complexity of the inputs in their sewer.

93 Samples were collected in the sewer and in the WWTP and their hydrocarbon contents

94 analyzed by gas chromatography-mass spectrometry. Parent and alkylated PAHs and alkanes

95 were quantified. The study also checks the preservation of specific hydrocarbon fingerprints

96 from the sewer to sewage sludge despite biological degradation in the sewer and the WWTP.

97

2. Materials and methods

Three sites A, B and C in rural districts of Lorraine, North East of France have been 101 selected for this study based on several criteria (Table 1 and details in Figure 1 of 102 supplementary information). First, all the sludges produced by the WWTPs presented a recurring PAH contamination of their sludges based on French regulation. Second, small rural

104 districts were preferred to important urban cities because of the limited number of suspected 105 PAH sources (low traffic, low industrialization). Finally, small and simple sewer networks 106 were chosen in order to facilitate the sampling and to limit the sample number. 
107 Site A gathers three villages with 1000 inhabitants in a rural environment. The district is

108 not industrialized except for a sawmill which is not connected to the sewer. Its WWTP is

109 made up of a primary treatment (sand, grit and grease removal), an aeration basin, a clarifier

110 and the sludges are finally stored in a silo which is emptied every year. Despite this rural

111 context, the sewage sludges have recorded PAH contamination for four successive years. In

112 December 2003, two samples of sewage sludge were collected in the silo A0-Slu1 and in the

113 aeration basin A0-Slu2. Six samples were taken in the sewer at five different locations (A1 to

114 A5) allowing to differentiate the effluents from the three villages. According to the

115 accessibility of the sewer and water flow (null in some parts), approximately 3 L of

116 wastewater (abbreviated "ww") or sediments accumulated in the sewer (abbreviated "sed")

117 were sampled.

118 Site B is a small village of 400 inhabitants in the northern part of Lorraine which is highly

119 industrialized (coking plants and steel industries). The WWTP has a very simple treatment

120 system made up of a sedimentation tank with a sand bed filter. In March 2004, three samples

121 (B1-sed to B3-sed) were collected in the sewer delimitating three areas of the village. At the

122 time of the sampling, a fuel storage tank was leaking in the village and a smell of fuel could

123 be clearly noticed when sampling the sewer at location B1. The wastewaters were sampled at

124 the entrance of the WWTP (B0-ww). Finally, four samples of sludge were collected in

125 different parts of the sedimentation tank to check the homogeneity of the sediments in the

126 tank (B0-slul to B0-slu4).

127 Site $\mathrm{C}$ consists of three villages $20 \mathrm{~km}$ far from a big city and gathers 2500 inhabitants.

128 The WWTP treats wastewaters from a large watershed with diversified activities: agriculture,

129 forestry, industries including trucking companies, printing works and other unidentified

130 activities. The WWTP is quite similar to that of site A with a screening process, an aeration

131 basin and a clarifier. In July 2004, five samples (C1 to C5) were taken in different locations of 
132 the sewer in order to differentiate the effluents generated in the industrial park (C1), and in

133 residential areas $(\mathrm{C} 2$ to $\mathrm{C} 5)$. Two wastewater samples $(3 \mathrm{~L})$ were collected at the entrance of

134 the WWTP serving two villages (residential areas) plus an industrial zone (C1-ww1) as well

135 as the third village with agricultural activity (C0-ww2). Finally, two sludges were sampled

136 (C0-slu1 and C0-slu2).

137 Water and sludge samples were collected with aluminum pans and stored in glass 138 containers. Utensils and containers were carefully washed with solvents before use to avoid 139 contamination.

\subsection{Sample preparation and extraction}

142 The sediments and sludges were preserved in a freezer before their extraction within a few

143 weeks after their collection. Wastewater samples (approximately $3 \mathrm{~L}$ ) were filtered on glass

144 fiber filters $(0.45 \mu \mathrm{m})$ using a pump in order to collect suspended matters. Suspended matters

145 on filters, sediments and sewage sludges were freeze-dried. Freeze-dried sediments and 146 sewage sludges were crushed and sieved $(250 \mu \mathrm{m})$.

147 The protocol used was a modification of Li et al. (2002). Five grams of each freeze-dried 148 sample were extracted with an accelerated solvent extractor (ASE; ASE200 Dionex ${ }^{\circledR}$ ) using

149 dichloromethane. Prior to extraction, the samples were spiked with a recovery surrogate 150 containing 2-fluorobiphenyle, d14-p-terphenylene and d14-dibenzo[ah]anthracene in order to 151 monitor the quality of the quantification method. The conditions of extraction by ASE were: $15211-\mathrm{mL}$ cells, $80^{\circ} \mathrm{C}, 100 \mathrm{bar}, 5$-min heat-up time, two cycles of 5 -min static time, $50 \%$ flush, 153200 seconds purge with nitrogen. The extracts obtained were concentrated to $1 \mathrm{ml}$ under $\mathrm{N}_{2}$ 154 using a TurboVap® Evaporation System. 
155 The organic extract was fractionated into aromatic, aliphatic and polar compounds by 156 liquid chromatography on alumina and silica previously washed with $200 \mathrm{~mL}$ of each solvent 157 (cyclohexane and dichloromethane) and activated at $150^{\circ} \mathrm{C}$ for $4 \mathrm{~h}$.

158 The concentrated extracts were transferred to a 5 g-alumina column $(6 \mathrm{~mm}$ i.d. $\times 20 \mathrm{~cm}$ in

159 length) and eluted with dichloromethane to obtain a hydrocarbon fraction (aromatic + 160 aliphatic). Dichloromethane was then exchanged with cyclohexane without evaporation to 161 dryness. The concentrated hydrocarbon fraction in $1 \mathrm{~mL}$ of cyclohexane was then transferred 162 to a 5 g-silica gel column (6 mm i.d. $\times 200 \mathrm{~mm}$ in length) and eluted with $12 \mathrm{~mL}$ of hexane to 163 recover the aliphatic fraction. The silica gel column was then eluted with a 164 hexane/dichloromethane mixture $(65: 35, \mathrm{v}: \mathrm{v})$. The two hydrocarbon fractions were 165 concentrated to $1 \mathrm{~mL}$ under $\mathrm{N}_{2}$.

\subsection{Analysis and quantification}

168 The GC-MS analyses of the aliphatic and aromatic fractions were performed in an Agilent

169 Technologies $6890 \mathrm{GC}$ coupled to an Agilent Technologies 5973 mass spectrometer, using an 170 injector in splitless mode, a $60 \mathrm{~m} \mathrm{DB}-5 \mathrm{~J} \& \mathrm{~W}, 0.25 \mathrm{~mm}$ id; $0.1 \mu \mathrm{m}$ film fused silica column. 171 The temperature program was $70-130^{\circ} \mathrm{C}$ at $15^{\circ} \mathrm{C} \cdot \mathrm{min}^{-1}$, then $130-315^{\circ} \mathrm{C}$ at $3^{\circ} \mathrm{C} \cdot \mathrm{min}^{-1}$, 172 followed by an isothermal stage at $315^{\circ} \mathrm{C}$ during $15 \mathrm{~min}$ (constant helium flow of $1 \mathrm{~mL} \cdot \mathrm{min}^{-1}$ ). 173 Injection volume was $1 \mu 1$.

174 Quantifications of parent PAHs (26) and alkylated PAHs were performed using single 175 ion monitoring mode and were based on the application of perdeuterated compounds as 176 internal standards (acenaphthene- $d_{10}$, chrysene- $d_{12}$, naphthalene- $d_{8}$, perylene- $d_{12}$ and 177 phenanthrene- $\left.d_{10}\right)($ Jeanneau et al., 2008). Peak areas were converted into concentration using 178 response factors determined from multiple injections of a certified $\mathrm{PAH}$ calibration mixture at 
179 various concentrations ( 0.5 to $8 \mathrm{ppm})$. Alkylated PAH compounds were quantified using the 180 response factor of the parent PAHs.

181 Cholestane- $\mathrm{d}_{6}$ and $n$-tetracosane- $\mathrm{d}_{50}$ were added to the aliphatic fraction as internal 182 standards in order to quantify the $n$-alkanes, the Unresolved Complex Mixture (UCM) and the 183 hopanes. Quantitative data were calculated by comparison of the peak areas in the extracted 184 ion current chromatogram $(\mathrm{m} / \mathrm{z}=57$ for $n$-alkanes, $\mathrm{m} / \mathrm{z}=191$ for hopanes $; \mathrm{m} / \mathrm{z}=183$ for 185 isoprenoids $; \mathrm{m} / \mathrm{z}=95$ for $\mathrm{UCM}$ ) ) with the peak areas of the internal standards.

\subsection{Organic geochemical ratios}

188 Molecular ratios were calculated from the different hydrocarbon concentrations. Their 189 significance is presented as supplementary information (Table 1). Moreover, the Carbon 190 Preference Index (CPI) that measures the ratio of odd to even carbon numbered $n$-alkanes was calculated as :

$$
C P I=\frac{1}{2} \times\left(\frac{C 25+C 27+C 29+C 31+C 33}{C 24+C 26+C 28+C 30+C 32}+\frac{C 25+C 27+C 29+C 31+C 33}{C 26+C 28+C 30+C 32+C 34}\right)
$$

The low/high molecular weight $n$-alkanes (LMW/HMW $\left.{ }_{\text {Ali }}\right)$ was quantified by the ratio C12-C20 / C21-C40 n-alkanes (LMW/HMW ali) (Colombo et al., 1989).

\section{Results}

\subsection{Polycyclic aromatic hydrocarbons}

The sum of 16 EPA priority PAHs ranged between 17 and $73 \mu \mathrm{g} \cdot \mathrm{g}^{-1} \mathrm{dw}$ in the sewage sludges (Table 2) and no sludge was found to comply with the French regulation (for detailed analyses of $16 \mathrm{PAH}$, see Table 2 of supplementary information). The distributions of the 16

201 PAHs (Figure 1 and Table 2) were quite similar from one sludge to another: dominated by Benzo $(b+j)$ fluoranthene $(B(b+j) F)$, enriched in HMW PAHs (LMW/HMW ${ }_{\mathrm{PAH}}$ ranging 
204 Sediments collected in the sewers showed PAH concentrations ranging between 5 and 118 $205 \mu \mathrm{g} \cdot \mathrm{g}^{-1} \mathrm{dw}$ and generally higher than in the sludges. They were generally enriched in LMW and 206 alkylated PAHs compared to sludges (Figure 1 and Table 2). Suspended matters in 207 wastewater usually showed lower PAH concentrations ( 0.8 to $45 \mu \mathrm{g} \cdot \mathrm{g}^{-1} \mathrm{dw}$ ) with higher 208 LMW/HMW ${ }_{\mathrm{PAH}}$ ratio (0.18 to 3.41$)$ and higher Alk/Par ratio (0.16 to 8.57) than sediments settled in the sewer (respectively 0.08 to 0.78 and 0 to 2.36 ). B0-ww, C1-ww and $\mathrm{C} 2-\mathrm{ww}$ 210 showed the highest values of the $\mathrm{LMW} / \mathrm{HMW}$ PAH ratio (above 1.5). B1-sed, B0-ww, C5-ww 211 and C5-sed were characterized by the predominance of alkylated PAHs (Alkyl/Par ratio above 212 1). The presence of LMW PAHs (2-3 rings) and the abundance of alkylated derivatives can be 213 characteristic of petroleum sources (Masclet et al., 1987; Yan et al., 2005).

214 The cross-correlation of several PAH ratios (Table 2 and figure 2) allowed inferring the 215 sources of PAH in the sewers and the sludges according to the work of Yunker et al. (2002). 216 Most of the PAH ratios proposed by Yunker et al. (2002) were tested and provided results 217 relatively consistent with the results proposed by the cross-plot $\mathrm{Fl} /(\mathrm{Fl}+\mathrm{P})$ vs. $\mathrm{C} 0 /(\mathrm{C} 0+\mathrm{C} 1) \mathrm{P}-$ 218 A (Figure 2). The PAHs of most of the samples originated from combustion. Only four 219 samples, C5-ww, C5-Gr, B0-ww and C5-sed had a $\mathrm{C} 0 /(\mathrm{C} 0+\mathrm{Cl})$ Phen-Ant ratio below 0.5 indicating a petroleum source of PAHs. Four samples, C5-ww, C5-Gr, C0-Slu1 and C0-Slu2 had a $\mathrm{Fl} /(\mathrm{Fl}+\mathrm{Py})$ ratio below 0.4 also implying a petroleum source.

From the detailed examination of PAHs for each sampling site, it arises that PAHs measured in the samples of site A were only from pyrogenic sources.

The site B showed the highest PAH concentrations. Suspended matter at the entrance of 225 the WWTP (B0-ww) clearly contained petrogenic PAHs according to $\mathrm{LMW} / \mathrm{HMW}_{\mathrm{PAH}}$, $226 \mathrm{Alk} / \mathrm{Par}$ and $\mathrm{C} 0 /(\mathrm{C} 0+\mathrm{C} 1) \mathrm{P}-\mathrm{A} . \mathrm{Fl} /(\mathrm{Fl}+\mathrm{P})$ did not provide such a clear conclusion and rather 227 indicated a petroleum combustion source. All the ratios calculated for sludges B0-Slu2 to B0228 Slu4 as well as for sediments B2-sed and B3-sed showed a clear combustion source. B1-sed 
229 had an intermediate position and most of the ratios (figure 2 and Table 3). They were between

230 those obtained for B0-ww (representing a petroleum influence) and those calculated for B0-

231 Slu2 to Slu4 (representing an unequivocal combustion input). This petroleum input is

232 consistent with the observation made on the site B1 where a smell of fuel was noticed at the

233 time of the sampling. B0-slu1, the closest to the entrance was slightly influenced as indicated

234 by the Alkyl/Par, LMW/HMW ${ }_{\mathrm{PAH}}$ ratio slightly higher than in B0-Slu2 to Slu4 and

$235 \mathrm{C} 0 /(\mathrm{C} 0+\mathrm{C} 1) \mathrm{P}-\mathrm{A}$ slightly lower.

236 At the site $\mathrm{C}$, the PAH distribution in the sludges was dominated by several compounds

237 identified as diisopropylnaphthalenes which were not quantified. These compound mixtures

238 are used as solvents in the manufacturing of printing materials or in agriculture as plant

239 growth regulators (Brzozowski et al., 2002). Their abundance in the sewer at $\mathrm{C} 1$ and in the

240 sludges is probably related to the important printing activities developed in the industrial park.

241 Besides these compounds, the PAH distribution and the different aromatic ratios clearly

242 identified a petroleum contribution in the sample C5 (corresponding to the village with

243 agricultural activities). In the other parts of the sewer ( $\mathrm{Cl}$ and $\mathrm{C} 2)$, low molecular weight

244 PAHs (Figure 1) were significantly abundant (LMW/HMW $\mathrm{PAH}>3$ ) but the other aromatic

245 ratios did not allow to conclude to a petrogenic contribution (Table 3). This specific PAH

246 distribution is probably related to the industrial activity developed at the site $\mathrm{C} . \mathrm{Fl} /(\mathrm{Fl}+\mathrm{Py})$

247 and $\mathrm{BaA} /(\mathrm{BaA}+\mathrm{Chr})$ were the only ratios to suggest a petrogenic input in sludges with values

248 in the same range as in the samples C5.

\subsection{Aliphatic hydrocarbons}

251 The detailed analysis of aliphatic hydrocarbons and the calculation of simple ratios 252 provided complementary information on PAHs and other hydrocarbon contributions (Table 2 253 and figure 3 ). In all samples, $n$-alkane concentrations were higher than PAH concentrations (1 
254 to 10 times higher). $n$-Alkane concentration was the highest at the site $\mathrm{B}$ with an average

255 value of $684 \mu \mathrm{g} \cdot \mathrm{g}^{-1} \mathrm{dw}$, in lower concentration at site $\mathrm{C}\left(245 \mu \mathrm{g} \cdot \mathrm{g}^{-1}\right)$ and the lowest at site A

$256\left(162 \mu \mathrm{g} \cdot \mathrm{g}^{-1}\right)$. The $n$-alkane concentration generally decreased from the sewer to the sewage

257 sludge. Hopanes were present in all the samples and their distributions typical from mature

258 fossil fuels were rather identical from one sample to another. Their presence attests to the

259 general contamination by petroleum products such as road asphalt imported into the sewer

260 through run-off that is also observed in aquatic sediments (Faure et al., 2000).

261 The three sites offered contrasted alkane distributions. At the site A (figure 3, table 2), the

$262 n$-alkane distributions were quite similar from one sample to another with the predominance

263 of HMW $n$-alkanes (LMW/HMW ${ }_{\text {ali }}$ ratios between 0.04 and 0.4 ) and high CPI ratios (1.6 to

264 3.9). This is typical of the contribution of terrestrial plants in the sewer which is dominant for

265 samples A4, A5 and the two sludges (Wakeham, 1996). The LMW/HMW ali ratio remained

266 low in all samples.

267 At the site B (Figure 3, table 2), the predominance of LMW n-alkanes and the presence of

268 the two isoprenoids, pristane and phytane in the sample, B1 were assigned to an important

269 input of fuel. This petroleum input was already evidenced with the PAH ratios and is

270 confirmed and better identified thanks to its specific $n$-alkane distribution. The CPI of $n$ -

271 alkanes in the sewer was close to 1.5 and confirmed the predominance of petroleum input

272 over terrestrial plant input. Finally, the low abundance of hopanes was another element to

273 conclude to a fuel input. A very specific distribution was observed in the sample B0-ww at

274 the entrance of the WWTP. It was dominated by pristane and phytane and no LMW n-alkane

275 was identified. This distribution is typical of weathered oils (Palmer, 1993) and could be the

276 result of the biodegradation of a fuel. This suggests the presence of an old contamination that

277 entered the sewer near the entrance of the WWTP. We have no clear evidence of the

278 relationship between the fuel identified at B1 and this weathered fuel. These very specific 
279 fingerprints in the sewer were also evidenced in the sewage sludges although they were less

280 pronounced. The fuel contribution was important in the sludge B0-Slul close to the entrance

281 of the WWTP but decreased in the sludges sampled further from the entrance (B0-Slu2 to

282 Slu4). The weathered fuel also influenced the composition of the sludge B0-Slul by

283 decreasing its ratios $\mathrm{C}_{17} /$ pristane or $\mathrm{C}_{18} /$ phytane compared to $\mathrm{B} 0$-Slu2 to B0-Slu4 (only the

284 chromatogram of B0-Slu3 is shown).

285 The site $\mathrm{C}$ (Figure 3 , table 2 ) offered a wide variety of $n$-alkane distributions revealing

286 complex inputs of hydrocarbons. Samples $\mathrm{C} 1$ located in the industrial park showed an

287 uncommon $n$-alkane distribution dominated by the even-numbered high molecular weight $n$ -

288 alkanes in the range $n-\mathrm{C} 20-n-\mathrm{C} 40$. This specific distribution, although diluted by the other

289 inputs was also observed in the sludges and it lowered significantly their CPI which were the

290 lowest of any sludge (1.2-1.3). We could relate this contamination to the presence of

291 diisopropylnaphthalenes in the aromatic fraction although we have no further evidence. It was

292 observed in the suspended matters in the sewer but largely attenuated $\mathrm{C} 1$-sed. The abundance

293 of low molecular weight $n$-alkanes in samples C5 allowed identifying a contribution of

294 refined petroleum products similar to the one observed at site B and assigned to an input of

295 fuel. This petroleum contribution was very important in the samples C5-ww and C5-Gr but

296 diluted by a terrestrial plant input in the sample C5-sed as indicated by the high CPI and a

297 quite low $\mathrm{LMW} / \mathrm{HMW}_{\text {ali }}$ ratio. The sample C5-ww was also characterized by the abundance

298 of the hopanes $\left(236 \mu \mathrm{g} \cdot \mathrm{g}^{-1} \mathrm{dw}\right)$. The sample C2-ww was characterized by a low CPI (1.27), the

299 predominance of HMW $n$-alkanes $(\mathrm{LMW} / \mathrm{HMWali}=0.0)$ and the abundance of the hopanes

$300\left(106 \mu \mathrm{g} \cdot \mathrm{g}^{-1} \mathrm{dw}\right)$. This distribution suggests a contribution of heavy petroleum products. The

301 samples C3-ww and C4-ww showed $n$-alkanes distributions dominated by terrestrial plant

302 inputs (chromatograms not shown). 


\subsection{Unresolved Complex Mixture (UCM)}

305 The UCM concentrations varied from one sample to another. They were generally high 306 (average of $6400 \mu \mathrm{g} \cdot \mathrm{g}^{-1} \mathrm{dw}$ with a standard deviation of $7925 \mu \mathrm{g} \cdot \mathrm{g}^{-1} \mathrm{dw}$ ) but consistent with

307 results previously published by other authors (Moreda et al., 1998; Rocher et al., 2004a).

308 They were attributed to the presence of weathered crude oils and some refined products such 309 as lubricating oils or biodegraded petroleum residues. They were positively correlated to the

310 hopane concentration with a Pearson correlation coefficient of 0.89 . Three samples showed 311 high UCM concentrations, C2-ww, C5-ww and C5-gr. The important HMW UCM of C5-ww

312 and C5-gr is associated with a specific distribution of $n$-alkanes and the abundance of hopanes

313 which strongly suggests an important contamination by lubricating oil. These features are less

314 pronounced in sample C2-ww but could indicate a small contamination by these petroleum 315 products.

316 Another important point to consider is the shape of the UCM which is very characteristic

317 of the inputs (Supplementary information, Figure 2)(Kaplan et al., 2001; Wang et al., 2004).

318 The absence of specific input or the dominance of terrestrial plant input is characterized by a

319 flat UCM shape such as in sample A3-sed. The presence of fuel oil is marked by a LMW

320 UCM with a typical bell shape such as in sample B1-sed and B0-ww. The presence of HMW

321 hydrocarbons from lubricating oil results in a HMW UCM with a bell shape as observed in

322 C5 samples. Finally, most of the samples and more specifically A5-sed and C3-ww show an

323 UCM classically observed in urban dust and road asphalt (Kaplan et al., 2001; Fernandes and 324 Brooks, 2003).

326 4. Discussion

327 Significance and pertinence of molecular indices for PAH source apportionment in sludges 
328 The complexity of the inputs in the sewers and the degradation of organic matter that takes

329 place in the sewer and the WWTP make PAH source apportionment difficult. Based on the

330 strict significance of PAH ratios (figure 2), most of the samples have an unambiguous

331 combustion fingerprint which is confirmed by the analysis of the aliphatic hydrocarbons. The

332 best example is probably the site A where all the PAH ratios indicate pyrogenic PAHs. The $n$ -

333 alkane distributions as well as the UCM abundances and other ratios do not provide any

334 supplementary information on the different contributions except an important dilution by

335 terrestrial plants. Only two samples have an unambiguous petroleum fingerprint (C5-Gr and

336 C5-ww) according to PAH ratios. In this case, hydrocarbon analysis provides crucial

337 information on the nature of the petroleum contributions. High UCM and hopane

338 concentrations, low CPI $(<1.5)$, high LMW/HMW $(>0.3)$ allow inferring inputs of lubricating

339 oil (or heavy petroleum residues) and fuel. Used lubricating oil commonly contains PAHs and

340 unburned fuel (Kaplan et al., 2001).

341 In several samples (B0-ww, B1-sed and B0-slu1), an obvious fuel contribution is identified

342 based on the aliphatic distribution but it is not clearly evidenced by the strict interpretation of

343 PAH ratios. It suggests either that the petrogenic input is not as important as the combustion

344 one or that biodegradation has altered the significance of molecular ratios.

346 Interest of sampling in the sewer - persistence of molecular indices in the sludges

347 The molecular indices calculated exclusively from sludge analyses are quite difficult to

348 interpret for two reasons: (i) they are the result of a mixture of multiple sources more or less

349 diluted with other organic matters and (ii) they have undergone a rather severe

350 biodegradation. Thus, molecular indices in sludges generally show the same molecular

351 fingerprint: most of the PAH ratios indicate mainly pyrogenic inputs and sometimes a mixed

352 petroleum and combustion contribution ; $n$-alkanes distributions are most of the time 
353 unimodal, UCM have generally the same shape turned toward HMW. The indices of a

354 specific and unusual input are very weak and it appears difficult to interpret a slight deviation

355 from the average sludge composition in terms of specific inputs.

356 The analyses of samples from the sewer give a more comprehensive insight of the inputs

357 and allow strengthening PAH source apportionment. Moréover, it provides a spatial screening

358 of the different inputs and can then help in identifying accidental inputs, contaminated area or

359 polluting activities. Sampling in the sewer also allows to obtain less degraded organic matter

360 and thus limits the change in molecular indices from source to receptors. When it was

361 possible to sample wastewater and sediments in the sewer at the same site, the comparison of

362 the composition of sediments and suspended particulate matter in wastewater showed a

363 systematic enrichment in LMW hydrocarbons suggesting less degraded hydrocarbons in

364 suspended particulate matter. Several authors (Zhang et al., 2005; Brandli et al., 2007;

365 Katsoyiannis et al., 2007) pointed out the instability of PAH ratios in different processes such

366 as biodegradation or composting. Our data show a systematic decrease of LMW/HMW

367 and Alk/Par from the sewer to the sludge also observed by Blanchard et al. (2001). This

368 suggests that the petroleum contribution is minimized in sludge because of its dilution and

369 more probably because of its preferential degradation during the transfer and the degradation 370 processes in the WWTP.

\section{Conclusions}

The first conclusion of this study is that, although questionable, PAH ratios provide at least

374 some leads to distinguish combustion from petroleum PAHs. But, they do not allow going

375 further into the interpretation of the origin of the petroleum or combustion inputs. The

376 identification of the different inputs can only be performed thanks to the aliphatic

377 hydrocarbons that will help in narrowing down the origin of petroleum products. In this way, 
$378 \mathrm{LMW} / \mathrm{HMW}_{\text {ali }}$ ratio, CPI and the abundance and the shape of the UCM are good source

379 indicators. However, there is a lack of indices to perform the same distinction between

380 multiple combustion sources since carbonaceous residues are generally depleted in aliphatic

381 hydrocarbons or do not have an unequivocal aliphatic distribution. Although Fernandes and

382 Brooks (2003) showed that every black carbon has its own molecular fingerprint, this

383 distinction becomes very difficult in the context of complex inputs, mixing petroleum and

384 combustion sources such as in sewer or sludge.

385 The second conclusion is that the multi-molecular approach can only be very efficient

386 when calculated from suspended matter or sediments sampled in the sewer and sludges.

387 Indeed, sewer samples allow spatial screening of the different inputs. When carefully chosen,

388 the sampling sites in the sewer integrate a lower number of hydrocarbon sources and data are

389 then easier to interpret. Moreover, the hydrocarbon fingerprints are better preserved from

390 biodegradation, water-washing and volatilization than in the sludge since they are close to the

391 emission source.

392 This study shows the pertinence of a multi-molecular approach combining PAH and 393 aliphatic ratios to identify the different hydrocarbon contributions in a sewer that end up in

394 the WWTP and finally in sewage sludges. It is particularly useful to point out the accidental

395 inputs of petroleum derivatives such as fuel or lubricating oils that overlap the diffuse inputs

396 of combustion PAHs brought by the run-off of the surfaces drained by the sewer. It can then

397 provide useful tools to manage the inputs in a sewer, improve the efficiency of a WWTP and

398 then lower PAH concentrations in sludges. The application of this multi-molecular approach

399 to samples collected with auto-samplers or sediment traps placed into the sewer would

400 improve the methodology and provide not only qualitative information on PAH sources but

401 also a better quantification of these inputs. 
The authors would like to thank the "Agence de l'Eau Rhin-Meuse" for its financial Moselle et de Meuse" for their precious help in the choice of pertinent sampling sites.

407

\title{
References
}

\begin{abstract}
Aboul-Kassim, T.A.T., Simoneit, B.R.T., 1995. Aliphatic and Aromatic Hydrocarbons in Particulate Fallout of Alexandria, Egypt: Sources and Implications. Environ. Sci. Technol. 29, $2473-2483$.

Blanchard, M., Teil, M.-J., Ollivon, D., Garban, B., Chestérikoff, C., Chevreuil, M., 2001. Origin and distribution of polyaromatic hydrocarbons and polychlorobiphenyls in urban effluents to wastewater treatment plants of the paris area (FRANCE). Water Res. 35, 3679-3687.
\end{abstract}

Brandli, R.C., Bucheli, T.D., Kupper, T., Mayer, J., Stadelmann, F.X., Tarradellas, J., 2007. Fate of PCBs, PAHs and their source characteristic ratios during composting and digestion of source-separated organic waste in full-scale plants. Environ. Pollut. 148, 520-528.

Brzozowski, R., Skupinski, W., Jamroz, M.H., Skarzynski, M., Otwinowska, H., 2002. Isolation and identification of diisopropylnaphthalene isomers in the alkylation products of naphthalene. J. Chromatogr. A 946, 221-227.

Bucheli, T.D., Blum, F., Desaules, A., Gustafsson, O., 2004. Polycyclic aromatic hydrocarbons, black carbon, and molecular markers in soils of Switzerland. Chemosphere 56, 1061-1076.

Budzinski, H., Jones, I., Bellocq, J., Piérard, C., Garrigues, P., 1997. Evaluation of sediment contamination by polycyclic aromatic hydrocarbons in Gironde estuary. Mar. Chem. $58,85-97$.

Colombo, J.C., Pelletier, E., Brochu, C., Khalil, M., Catoggio, J.A., 1989. Determination of hydrocarbon sources using n-alkane and polyaromatic hydrocarbon distribution indexes. Case study: Rio de la Plata Estuary, Argentina. Environ. Sci. Technol. 23, $888-894$.

Dai, J., Xu, M., Chen, J., Yang, X., Ke, Z., 2007. PCDD/F, PAH and heavy metals in the sewage sludge from six wastewater treatment plants in Beijing, China. Chemosphere 66, 353-361.

Faure, P., Landais, P., Schlepp, L., Michels, R., 2000. Evidence for diffuse contamination of river sediments by road asphalts particles. Environ. Sci. Technol. 34, 1174-1181.

Fernandes, M.B., Brooks, P., 2003. Characterization of carbonaceous combustion residues: II. Nonpolar organic compounds. Chemosphere 53, 447-458.

Jardé, E., Mansuy, L., Faure, P., 2005. Organic markers in the lipidic fraction of sewage sludges. Water Res. 39, 1215-1232.

Jeanneau, L., Faure, P., Montarges-Pelletier, E., 2008. Quantitative multimolecular marker approach to investigate the spatial variability of the transfer of pollution from the Fensch River to the Moselle River (France). Sci. Total Environ. 389, 503-513. 
Kaplan, I.R., Lu, S.-T., Alimi, H.M., MacMurphey, J., 2001. Fingerprinting of High Boiling Hydrocarbon Fuels, Asphalts and Lubricants. Environmental Forensics 2, 231-248.

Katsoyiannis, A., Terzi, E., Cai, Q.-Y., 2007. On the use of PAH molecular diagnostic ratios in sewage sludge for the understanding of the PAH sources. Is this use appropriate? Chemosphere 69, 1337-1339.

Li, Y., Michels, R., Mansuy, L., Elie, M., Faure, P., 2002. Comparison of pressurized liquid extraction (PLE) with classical solvent extraction (SE) and microwave assisted extraction (MAE)-Application to the investigation of the artificial maturation of Mahakam coal. Fuel 81, 747-755.

Masclet, P., Bresson, M.A., Mouvier, G., 1987. Polycyclic aromatic hydrocarbons emitted by power stations, and influence of combustion conditions. Fuel 66, 556-562.

Moreda, J.M., Arranz, A., Fdez De Betono, S., Cid, A., Arranz, J.F., 1998. Chromatographic determination of aliphatic hydrocarbons and polyaromatic hydrocarbons (PAHs) in a sewage sludge. Sci. Total Environ. 220, 33-43.

Motelay-Massei, A., Ollivon, D., Garban, B., Tiphagne-Larcher, K., Zimmerlin, I., Chevreuil, M., 2007. PAHs in the bulk atmospheric deposition of the Seine river basin: Source identification and apportionment by ratios, multivariate statistical techniques and scanning electron microscopy. Chemosphere 67, 312-321.

Palmer, S.E., 1993. Effect of biodegradation and water-washing on crude oil composition. In: Engel, M.H., Macko, S.A. (Eds.). Organic Geochemistry: Principles and Applications. Plenum Press, New York, pp. 511-533.

Rocher, V., Azimi, S., Moilleron, R., Chebbo, G., 2004a. Hydrocarbons and heavy metals in the different sewer deposits in the 'Le Marais' catchment (Paris, France): stocks, distributions and origins. Sci. Total Environ. 323, 107-122.

Rocher, V., Garnaud, S., Moilleron, R., Chebbo, G., 2004b. Hydrocarbon pollution fixed to combined sewer sediment: a case study in Paris. Chemosphere 54, 795-804.

Wakeham, S.G., 1996. Aliphatic and polycyclic aromatic hydrocarbons in Black Sea sediments. Mar. Chem. 53, 187-205.

Wang, Y., Huang, Y., Huckins, J.N., Petty, J.D., 2004. Compound-Specific Carbon and Hydrogen Isotope Analysis of Sub-Parts per Billion Level Waterborne Petroleum Hydrocarbons. Environ. Sci. Technol. 38, 3689-3697.

Wilcke, W., 2000. Polycyclic aromatic hydrocarbons (PAHs) in soil - A review. J. Plant Nutr. Soil Sc. 163, 229-248.

Yan, B., Abrajano, T.A., Bopp, R.F., Chaky, D.A., Benedict, L.A., Chillrud, S.N., 2005. Molecular Tracers of Saturated and Polycyclic Aromatic Hydrocarbon Inputs into Central Park Lake, New York City. Environ. Sci. Technol. 39, 7012-7019.

Yunker, M.B., Macdonald, R.W., 2003. Alkane and PAH depositional history, sources and fluxes in sediments from the Fraser River Basin and Strait of Georgia, Canada. Org. Geochem. 34, 1429-1454.

Yunker, M.B., Macdonald, R.W., Brewer, R., Mitchell, R.H., Goyette, D., Sylvestre, S., 2002. PAHs in the Fraser River basin: a critical appraisal of PAH ratios as indicators of PAH source and composition. Org. Geochem. 33, 489-515.

Zhang, X.L., Tao, S., Liu, W.X., Yang, Y., Zuo, Q., Liu, S.Z., 2005. Source Diagnostics of Polycyclic Aromatic Hydrocarbons Based on Species Ratios: A Multimedia Approach. Environ. Sci. Technol. 39, 9109-9114. 
495 Table 1: Sample names and main characteristics of the three sampling sites. See Figure 1 of supplementary information for locations of sampling points on a map.

Table 2: PAH and alkane concentrations and main molecular ratios calculated from hydrocarbon concentrations. Max $\mathrm{PAH}=$ major $\mathrm{PAH} ; \mathrm{LMW} / \mathrm{HMW}_{\mathrm{PAH}}$ is the ratio of the 2-3 rings PAHs to the 4-6 rings PAHs; Alk/Par is the ratio of the sum of the alkyl-PAH (C1-C4

$\mathrm{Na} ; \mathrm{C} 1-\mathrm{C} 3 \mathrm{P} / \mathrm{A} ; \mathrm{Cl}-\mathrm{C} 2 \mathrm{~F} / \mathrm{P}$ ) to the sum of the parent PAHs with masses $128,178,202$;

$502 \mathrm{C} 0 /(\mathrm{C} 0+\mathrm{C} 1) \mathrm{P}-\mathrm{A}$ is the ratio of parent PAHs with mass $178(\mathrm{P}, \mathrm{A})$ to PAHs with mass 178

503 (A; P) plus their $\mathrm{Cl}$ alkyl homologues ; Max n-alkane = major aliphatic hydrocarbon ;

$504 \mathrm{UCM} / \mathrm{R}$ is the ratio of the concentration of unresolved complex mixture (UCM) to resolved

505 alkanes $(\mathrm{R}=n$-alkanes + hopanes + isoprenoids $)$.

Figure 1: PAH distribution normalized to the sum of the $16 \mathrm{PAH}$. The left column gathers samples of suspended particulate matter from the wastewaters collected in the sewer, the central column gathers sediments settled in the sewer, and the right column gathers sewage sludges. Na: Naphthalene; Acy: Acenaphthylene; Ace: Acenaphthene; F: Fluorene; P :

511 Phenanthrene; A : Anthracene; Fl : Fluoranthene; Py : Pyrene; BaA: Benzo(a)anthracene; Ch:

512 Chrysene; $\mathrm{B}(\mathrm{b}+\mathrm{j}) \mathrm{F}$ : Benzo(b)fluoranthene; BkF: Benzo(k)fluoranthene; BaP: Benzo(a)pyrene;

513 DhA: Dibenzo(ah)anthracene; Bghi: Benzo(ghi)perylene; IP: Indeno(123-cd)pyrene

Figure 2: $\mathrm{PAH}$ cross plot for the ratio $\mathrm{Fl} /(\mathrm{Fl}+\mathrm{Py})$ vs $\mathrm{C} /(\mathrm{C} \theta+\mathrm{C} 1) \mathrm{P}-\mathrm{A}$.

518 Phytane. 


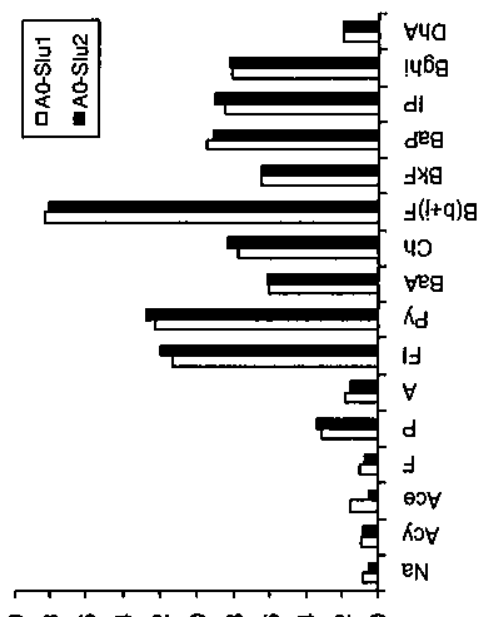

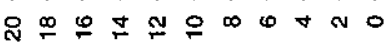
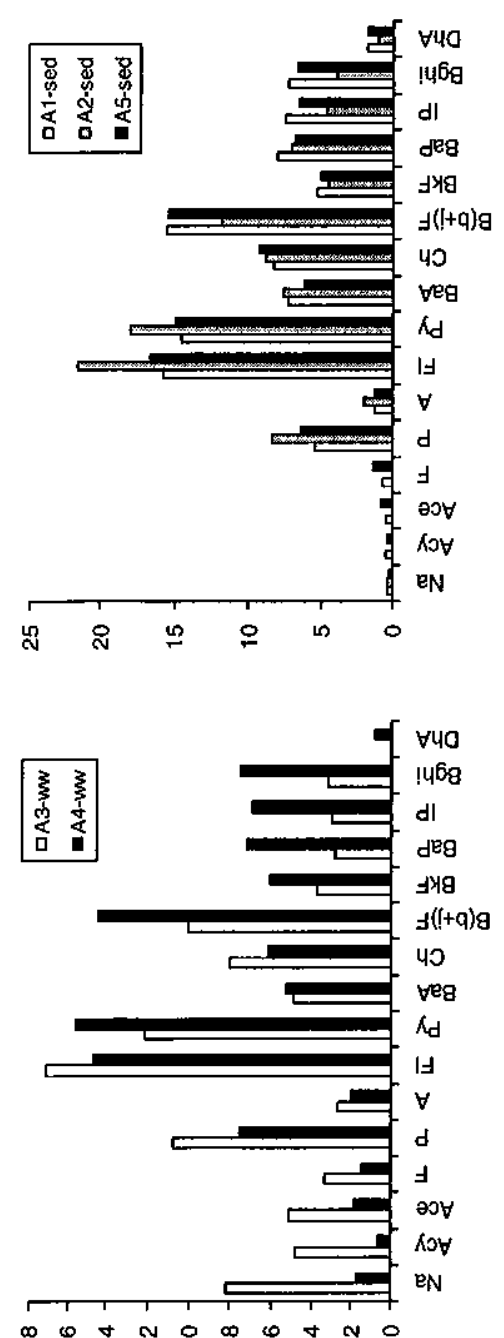

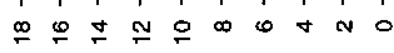
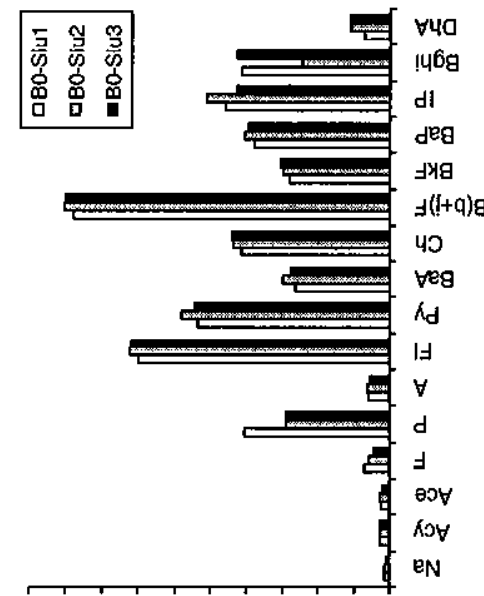

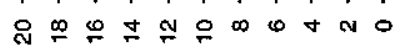
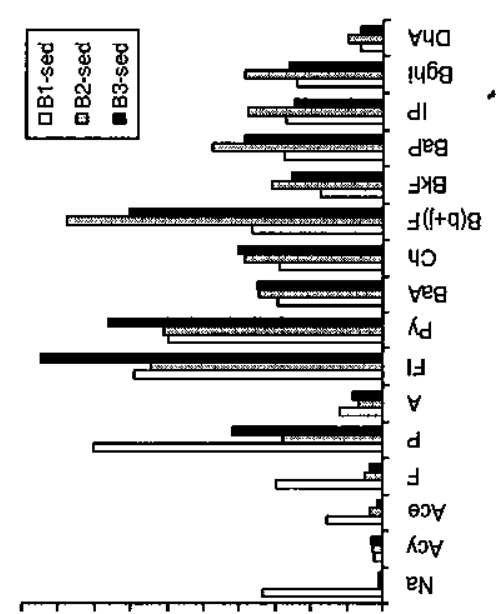

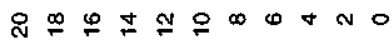

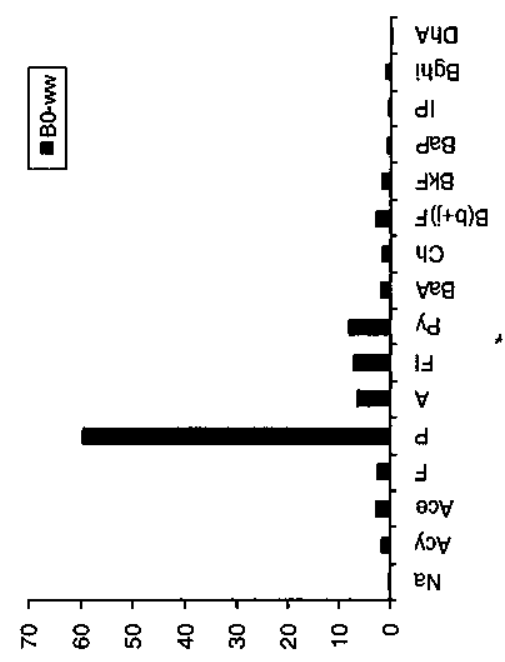

H $\forall$ d 9 . wns $10 \%$
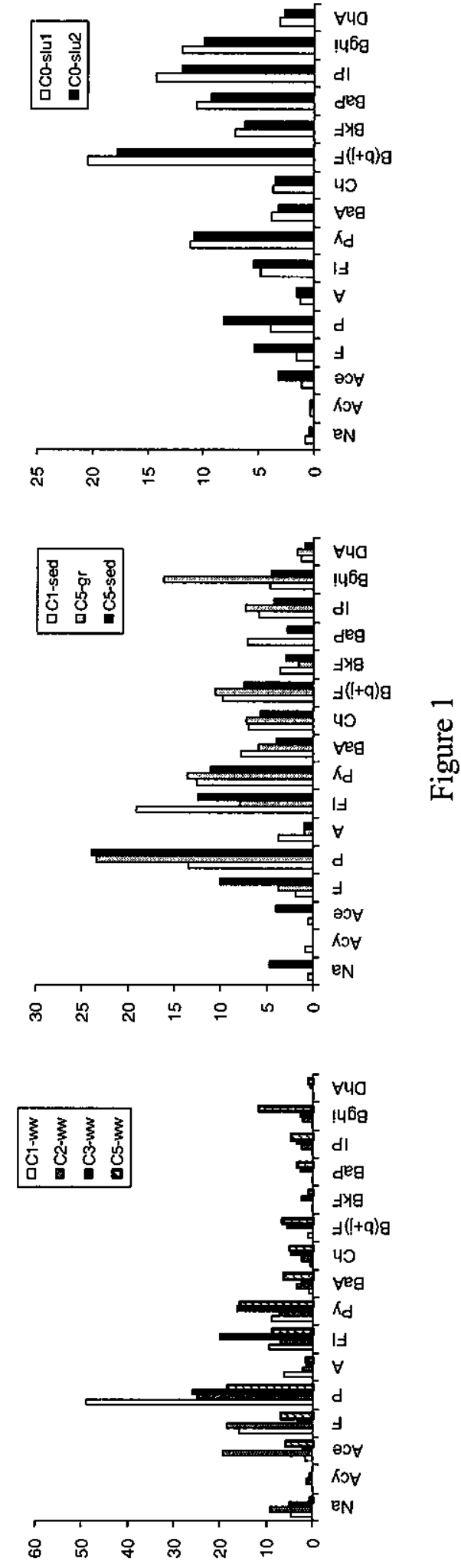

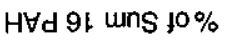




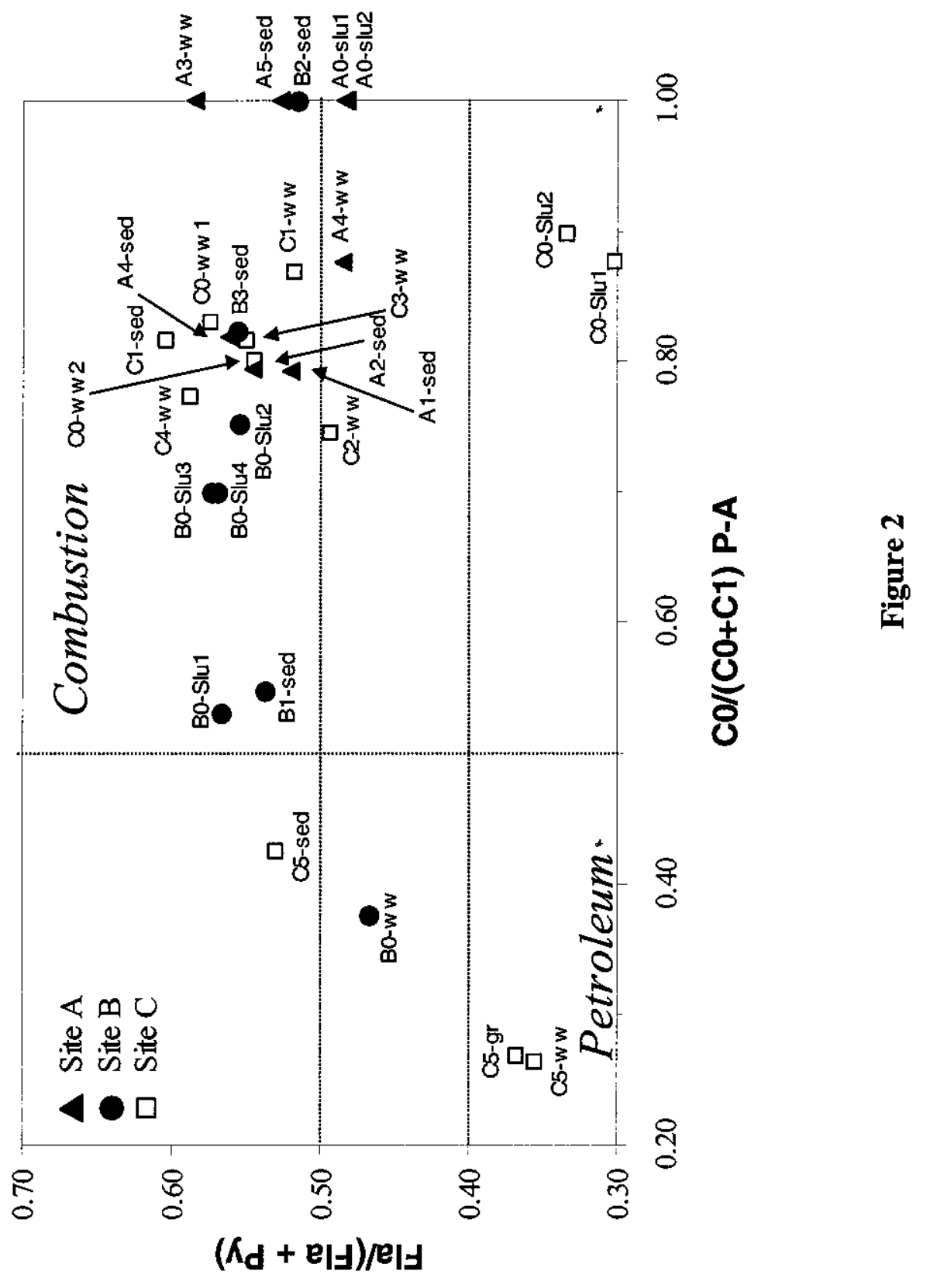



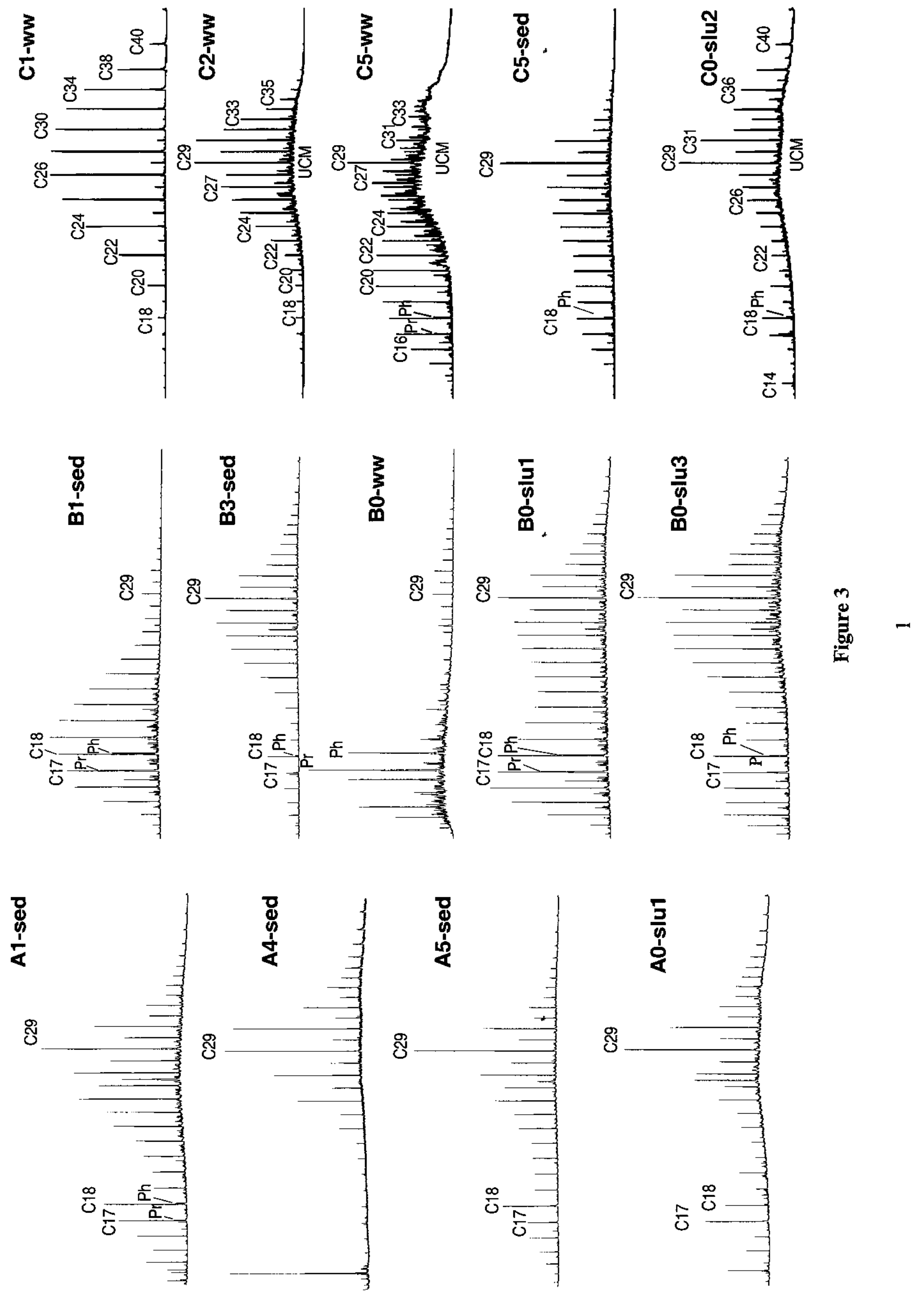
Table 1

\begin{tabular}{|c|c|c|}
\hline Abbreviation & Location & Main characteristics \\
\hline A0-Slul & Site A - WWTP & Sewage sludge in the WWTP Silo \\
\hline A0-Slu2 & Site A - WWTP & Sewage sludge in the WWTP aeration basin \\
\hline A1-sed & Site A - Sewer & $\begin{array}{l}\text { Sediments in the manhole at the confluence of villages } \\
1 \text { and } 2\end{array}$ \\
\hline A2-sed & Site A - Sewer & $\begin{array}{l}\text { Sediments in the manhole of the village } 3 \text { collecting } \\
\text { wastewater and runoff }\end{array}$ \\
\hline A3-ww & Site A - Sewer & $\begin{array}{l}\text { Wastewater in the manhole of the newest residential } \\
\text { part of village } 1\end{array}$ \\
\hline A4-ww & Site A - Sewer & $\begin{array}{l}\text { Wastewater in the manhole of the oldest residential part } \\
\text { of village } 1\end{array}$ \\
\hline A4-sed & Site A - Sewer & $\begin{array}{l}\text { Sediments in the manhole of the oldest residential part } \\
\text { of village } 1\end{array}$ \\
\hline A5-sed & Site A - Sewer & Sediments in the manhole of the whole village 1 \\
\hline B0-ww & Site B - WWTP & Wastewater at the entrance of the WWTP \\
\hline B0-Slu1 & Site B - WWTP & Sewage sludge in the sedimentation tank \\
\hline B0-Slu2 & Site B - WWTP & Sewage sludge in the sedimentation tank \\
\hline B0-Slu3 & Site B - WWTP & Sewage sludge in the sedimentation tank \\
\hline B0-Slu4 & Site B - WWTP & Sewage sludge in the sedimentation tank \\
\hline B1-sed & Site B - Sewer & Manhole of the village \\
\hline B2-sed & Site B - Sewer & Manhole of the village \\
\hline B3-sed & Site B - Sewer & Manhole of the village \\
\hline C0-wwl & Site C - WWTP & $\begin{array}{l}\text { Wastewater from villages } 1 \text { and } 2 \text { at the entrance of the } \\
\text { WWTP }\end{array}$ \\
\hline $\mathrm{C} 0-\mathrm{ww} 2$ & Site C - WWTP & $\begin{array}{l}\text { Wastewater from village } 3 \text { at the entrance of the } \\
\text { WWTP }\end{array}$ \\
\hline C0-slu1 & Site C - WWTP & Sewage sludge in the aeration basin \\
\hline C0-slu2 & Site C - WWTP & Sewage sludge in the silo \\
\hline $\mathrm{C} 1-\mathrm{ww}$ & Site C - Sewer & Wastewater in a manhole of the industrial park \\
\hline C1-sed & Site C - Sewer. & Sediments in a manhole of the industrial park \\
\hline C2-ww & Site C - Sewer & Wastewater in a manhole of a residential area \\
\hline C3-ww & Site C - Sewer & Wastewater in a manhole of villages 1 and 2 \\
\hline C4-ww & Site C - Sewer & Wastewater in a manhole of villages 1 and 2 \\
\hline C5-ww & Site C - Sewer & Wastewater in a manhole of village 3 \\
\hline C5-gr & Site C - Sewer & Grease in a manhole of village 3 \\
\hline C5-sed & Site C - Sewer & Sediments in a manhole of village 3 \\
\hline
\end{tabular}




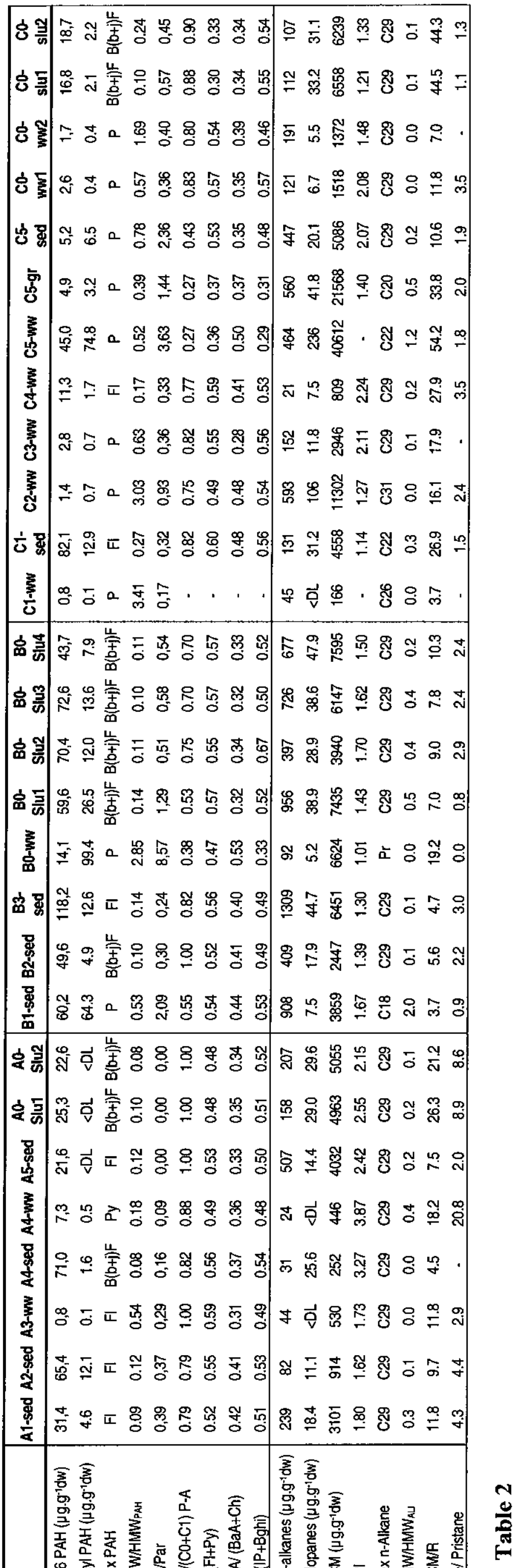




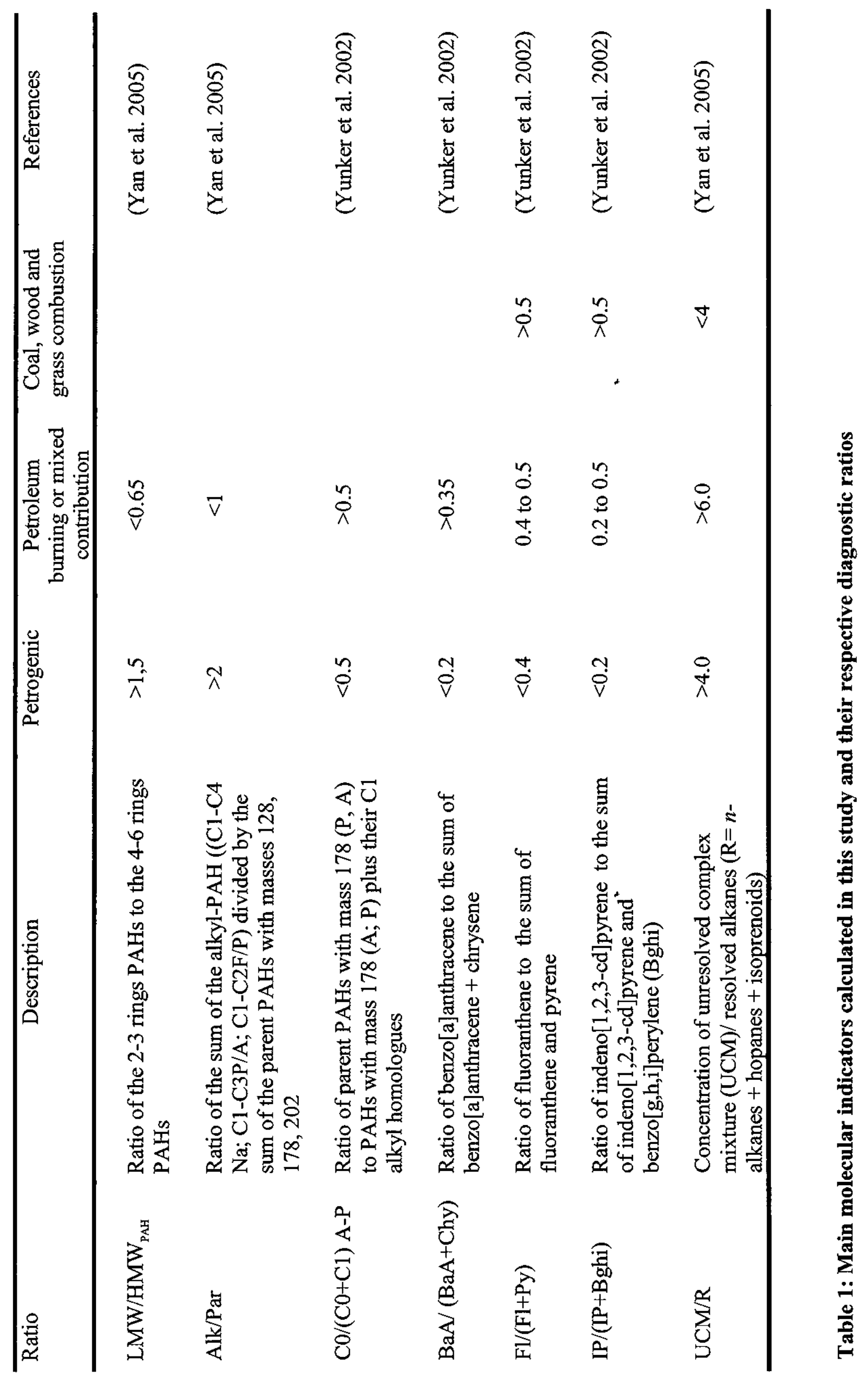




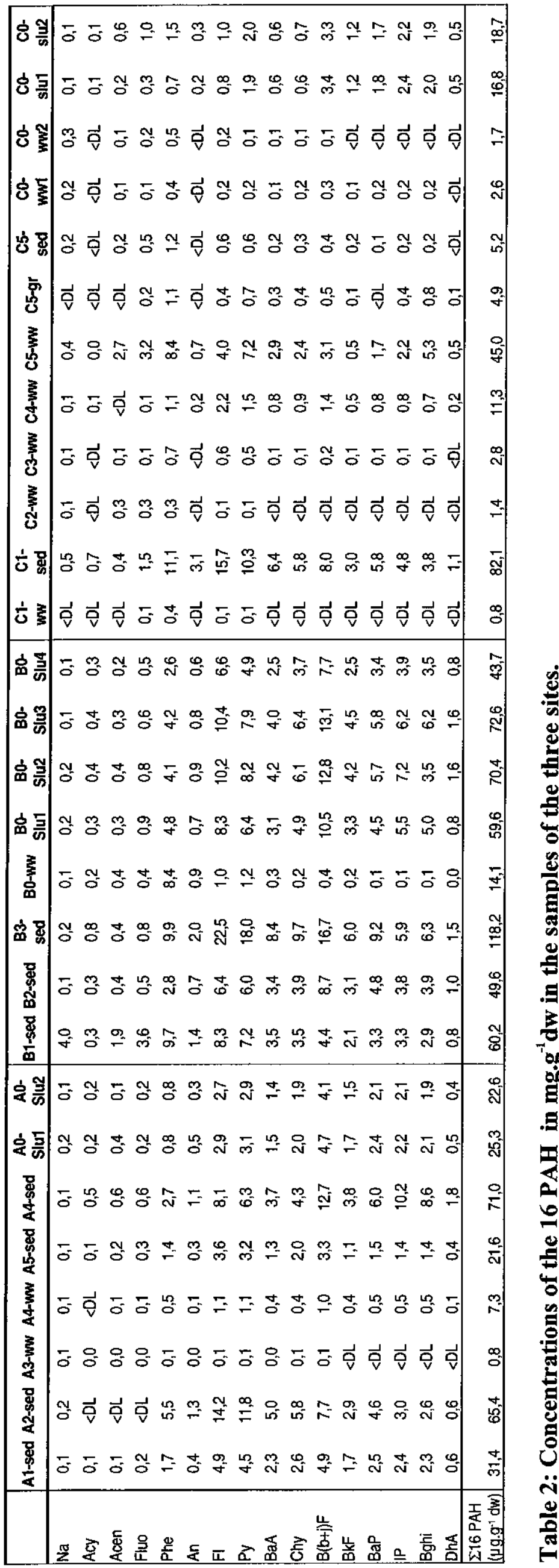



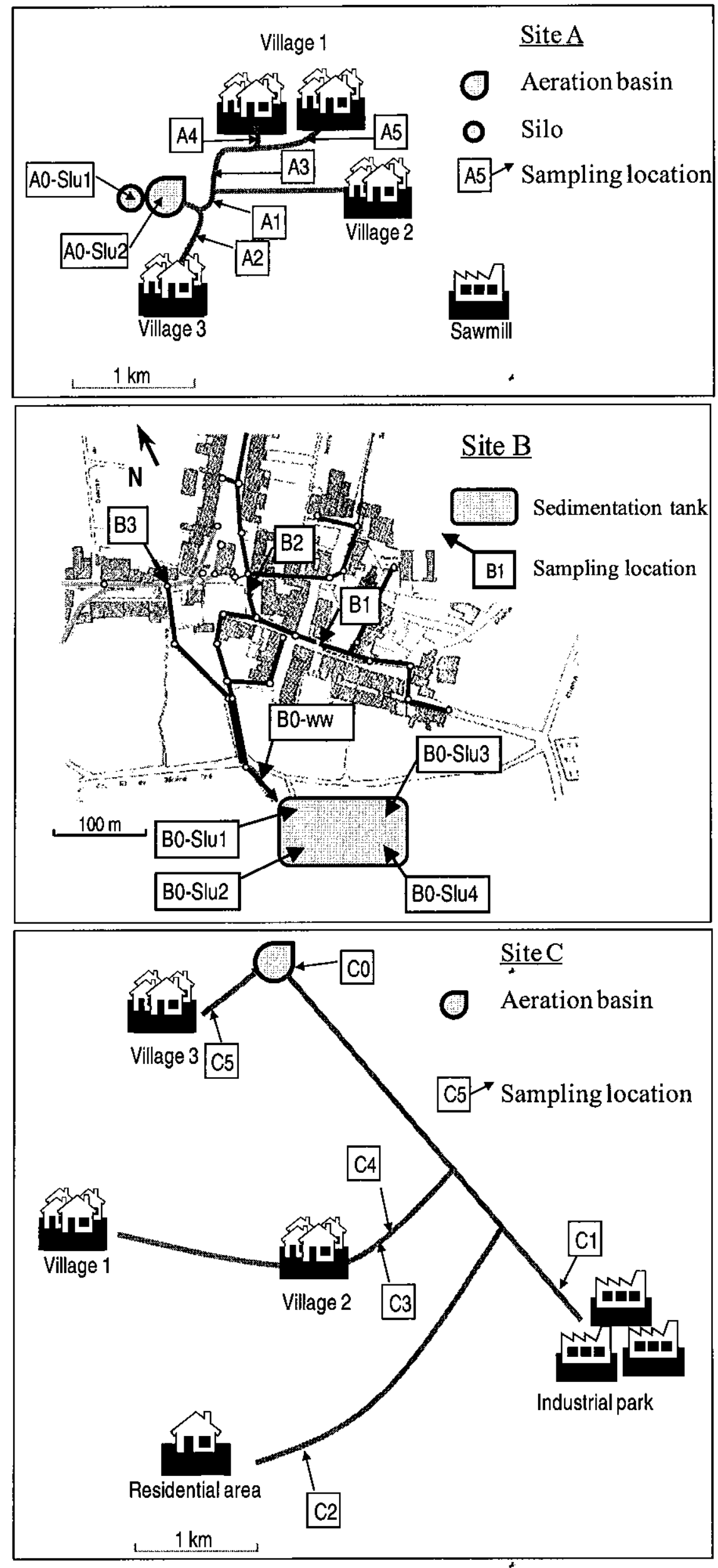

Figure 1: Detailed map of the three sampling sites 

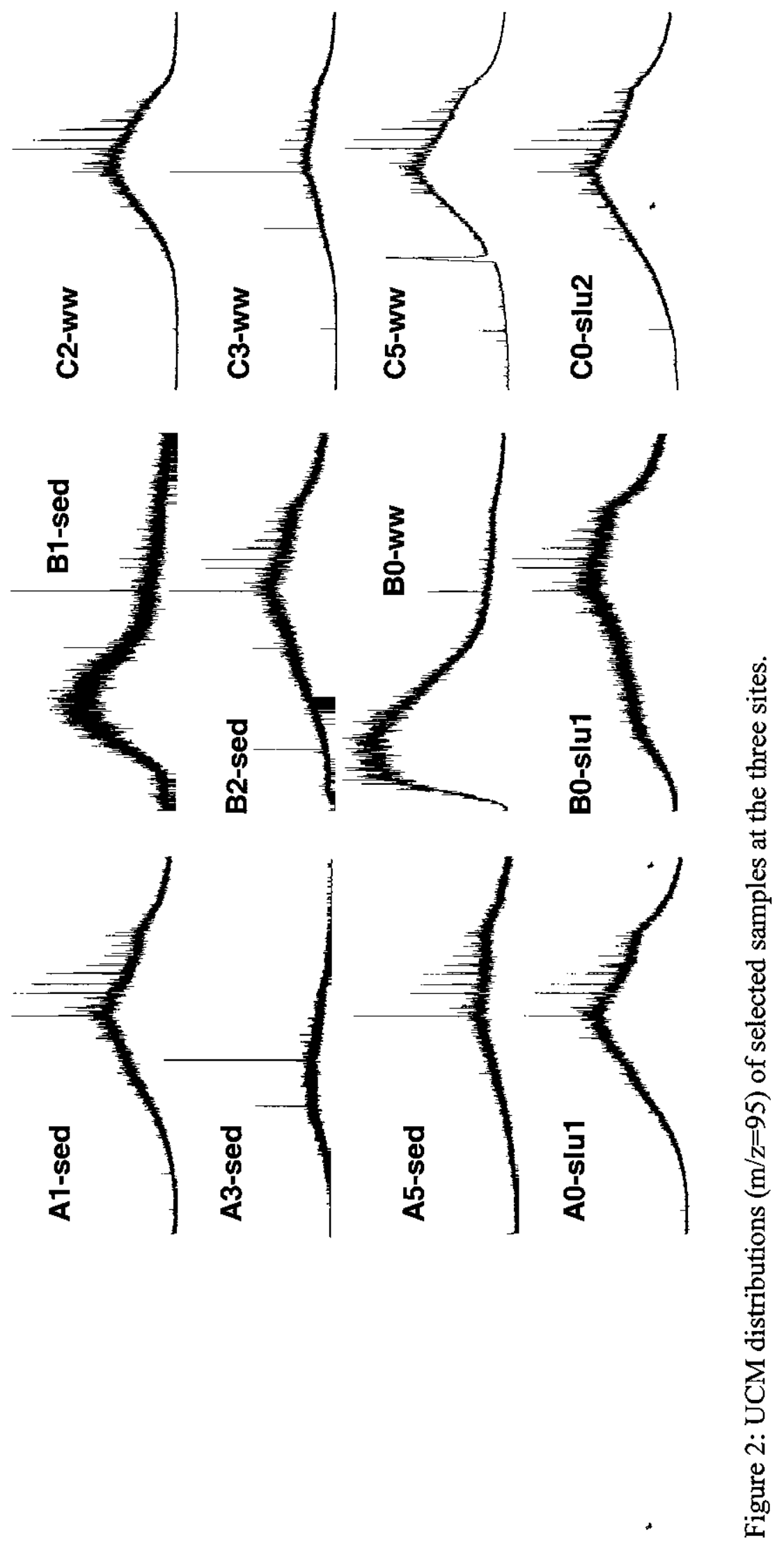